\title{
Conformational Variability in Sulfonamide Chalcone Hybrids: Crystal Structure and Cytotoxicity
}

\author{
Mirian R. C. de Castro, ${ }^{a}$ Ângelo Q. Aragão, ${ }^{a}$ Cameron C. da Silva,${ }^{a}$ Caridad N. \\ Perez, ${ }^{a}$ Darlene P. K. Queiroz, ${ }^{a}$ Luiz Henrique K. Queiroz Júnior, ${ }^{a}$ Stefânio Barreto, ${ }^{b}$ \\ Manoel O. de Moraes ${ }^{b}$ and Felipe Terra Martins ${ }^{*, a}$ \\ anstituto de Química, Universidade Federal de Goiás, 74001-970 Goiânia-GO, Brazil \\ ${ }^{b}$ Departmento de Fisiologia e Farmacologia, Universidade Federal do Ceará, \\ 60430-270 Fortaleza-CE, Brazil
}

\begin{abstract}
Four sulfonamide-chalcone derivatives were prepared and their crystal structure were elucidated by single-crystal X-ray diffraction technique. They were synthesized by Claisen-Schmidt condensation reaction between $N$-(4-acetylphenyl)benzenesulfonamide or $N$-(4-acetylphenyl)2,5-dichlorobenzenesulfonamide with benzaldehyde or $p$-nitrobenzaldehyde. Values of $Z^{\prime}>1$ are found in three compounds as a consequence of conformerism. The chalcone molecular backbones are featured by different levels of planarity in their conformers. Another conformational variability is in its benzenesulfonamide moiety. In the compound came from $\mathrm{N}$-(4-acetylphenyl) benzenesulfonamide and benzaldehyde, there is a rotation of ca. $180^{\circ}$ on the bond axis bridging the sulfonamide and chalcone motifs of one conformer if the two others are taken as references. The cytotoxic activity of all compounds synthesized here and of two other related sulfonamide chalcones was also assessed against three cancer cell lines (SF-295, HCT-8 and MDA-MB-435). The para-nitro compounds were the most active ones among all those tested, regardless of substitution pattern in benzenesulfonamide core.
\end{abstract}

Keywords: structural analyses and structure determination, structure-activity relationship, biological and pharmacological activities, bioactive compounds, molecular structure

\section{Introduction}

Compounds bearing sulfonamide moiety are well known to exhibit a broad range of pharmacological profiles. ${ }^{1,2}$ The recognition of their ability to interact with biological targets culminating in certain desired pharmacological response goes beyond promising in vivo and in vitro experiments carried out on laboratories. Many sulfonamide derivatives are used worldwide in the clinic for a long time as active pharmaceutical ingredients for treatment of bacterial and viral infections, hyperglycemia and hypertension, among others. ${ }^{3,4}$ This highlighted affinity of sulfonamides for macromolecules engaged in many human pathologies has attracted attention of medicinal chemists towards assessing such compounds against actual diseases. Recently, compounds owing at least an aromatic sulfonamide motif have demonstrated antitumor activity through diversified modes of action. ${ }^{5-7}$ These include since

*e-mail: felipe@ufg.br inhibiting tubulin assembly ${ }^{8}$ up to gene therapy mediated by functional suppression of transcriptional activators. ${ }^{9}$

Another compounds possessing wide spectrum of bioactivities are chalcones. ${ }^{10-12}$ They can be obtained from either natural sources or synthetic pathways, being used as intermediates of analogues with improved pharmacological profiles. ${ }^{13,14}$ Chalcone nomination does indicate the presence of a 1,3-diarylpropenone minimal framework, even though the possibility of attaching substituents at their aromatic rings is a recipe of getting new compounds of this class with tuned biological properties. ${ }^{13,15}$ For instance, 2-tosylaminochalcones has been investigated as platform to synthesis of biologically relevant 2,3-indolines. ${ }^{16}$ Concerning anticancer activity, chalcone motif does constitute one of the most important molecular basis for searching novel powerful and selective drugs. ${ }^{15,17}$ For instance, several 3,4,5-trimethoxychalcones have exhibited cytotoxicity to acute lymphoblastic leukemia cells through inhibition of tubulin assembly comparable to colchicine. ${ }^{18}$ Recently, a chalcone derivative with one amino group 
attached at one of its two phenyl rings has shown a potent antiproliferative effect against several cancer cell lines, which are resistant to tumor necrosis factor (TNF)-related apoptosis-inducing ligand (TRAIL). Furthermore, it was possible to observe that this compound does kill selectively tumor cells through early apoptosis instead of necrotizing them, without damaging healthy cells. ${ }^{19}$

When sulfonamide and chalcone moieties are fused, their biological profiles are conserved or even increased. To our knowledge, a series of sulfonamide derivatives fused to chalcone scaffold have been synthesized and in vitro tested against human tumor liver cancer (HEPG2). ${ }^{20}$ The compound with 4-methylbenzenesulfonamide and $p$-nitrophenyl has been a strong HEPG2 killer profile (Figure 1). Likewise, this compound and other three sulfonamide chalcone hybrids acted synergistically together with a single dose of $\gamma$-radiation against this cell line. In addition, it is believed that unsubstituted $\alpha, \beta$-unsaturated ketone system plays an anticancer pharmacophore role in such compounds. ${ }^{19-21}$ The activity of another sulfonamide chalcone against hepatocarcinoma is well documented through two mechanisms. It is the 4'-( $p$-toluenesulfonylamide)-4hydroxychalcone (TSAHC, Figure 1), a synthetic derivative inhibiting ( $i$ ) tumor multilayer growth and invasion, driven by the over-expressed TM4SF5 gene encoding a cell-surface glycoprotein involved in signal transduction for cell development and proliferation ${ }^{22}$ and (ii) inhibiting cytochrome P450 2J2 isoform also engaged in the promotion of tumor growth and proliferation. ${ }^{23}$ Sulfonamide chalcones do also present striking $\alpha$-glucosidase inhibiting property. ${ }^{16,24}$ TSAHC does also present such feature..$^{25}$ $\alpha$-Glucosidase enzyme is responsible to catalyze breaking lastly intake carbohydrates in the intestinal mucosa. So that its inhibition can delay glucose absorption and then, avoid postprandial hyperglycemia. Therefore, these hybrids are also candidates for anti-diabetic drugs besides anticancer ones.

Due to its promising pharmacological potential against several biological targets, TSAHC has been better investigated from a structural point of view. Its crystal structure was the only one reported for this compound series ${ }^{25}$ before we were interested in their crystallographic characterization. In sequence, crystal structure of two TSAHC analogs, which cytotoxicity is reported here (compounds $\mathbf{5}$ and $\mathbf{6}$ ), ${ }^{26}$ were elucidated by our research group. Not so much similar to TSAHC and its analogs, all of them owing arylsulfonamide moiety attached in the 1-phenyl group from chalcone scaffold in the para-position, crystal structure of some other related compound with arylsulfonamide bonded in the ortho-position of either 1-phenyl (two compounds) ${ }^{27,28}$ or 3-phenyl (six compounds) ) $^{29-34}$ ring from chalcone core has been also determined.<smiles>Cc1ccc(S(=O)(=O)Nc2ccc(C(=O)/C=C/c3ccc([N+](=O)[O-])cc3)cc2)cc1</smiles><smiles>Cc1ccc(S(=O)(=O)Nc2ccc(C(=O)/C=C/c3ccc(O)cc3)cc2)cc1</smiles>

Figure 1. Sulfonamide chalcone hybrids known for their promising antitumor properties. (a) Adapted from reference 20; (b) TSAHC: 4'-( $p$-toluenesulfonylamide)-4-hydroxychalcone, adapted from reference 22.

Based on the known pharmacological potential of compounds with both sulfonamide and chalcone skeletons and on the rareness of crystal structure elucidation thereof, which can play a key role in the comprehension of their biological profiles thorough full knowledge of inter- and intramolecular geometries, we here have prepared and analyzed by single-crystal X-ray diffraction technique four sulfonamide chalcone derivatives. Their cytotoxicity against three cancer cell lines, namely MDA-MB-435 (melanoma), HTC-8 (colon) and SF-295 (central nervous system) were likewise assessed. These compounds were synthesized by Claisen-Schmidt condensation reaction between $N$-(4-acetylphenyl)benzenesulfonamide or $N$-(4-acetylphenyl)-2,5-dichlorobenzenesulfonamide with benzaldehyde and $p$-nitrobenzaldehyde (Figure 2). To the best of our knowledge, the product from reaction between $N$-(4-acetylphenyl)-2,5-dichlorobenzenesulfonamide and $p$-nitrobenzaldehyde is new. The other three compounds

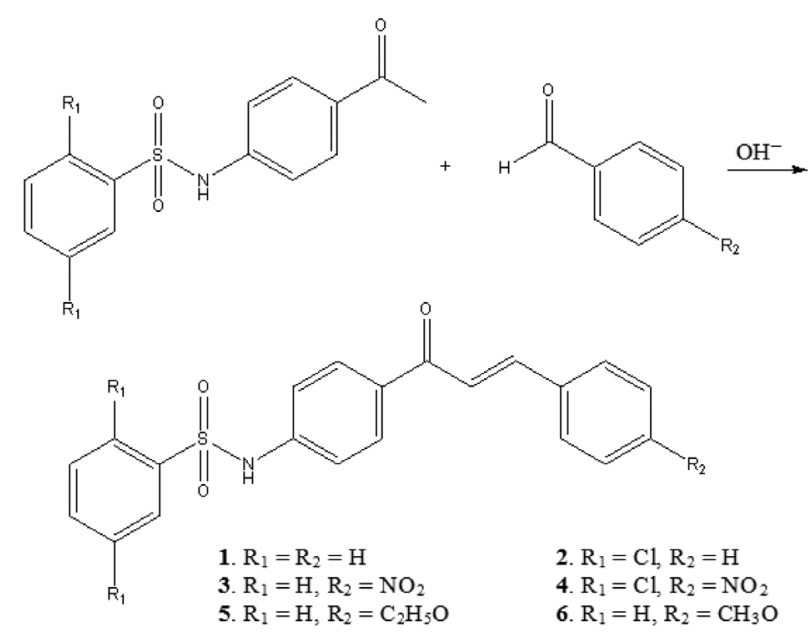

Figure 2. General scheme for synthesis of sulfonamide chalcones. 
are already known, ${ }^{35-39}$ even though their crystal structures have not been elucidated thus far. The nuclear magnetic resonance (NMR) data of two of these compounds (4 and 5) is also new (see Supplementary Information). A detailed structural inspection is presented in this study together with their cytotoxicity, which allowed us to understand the role of the 2,5-dichloro and para-nitro substituents in the conformational variability and biological activity.

\section{Results and Discussion}

\section{Crystal structures}

Even though the molecular structure differences between the compounds studied here, three of them, namely compounds $\mathbf{1 - 3}$, crystallize in the same crystal system triclinic and in the centrosymmetric space group $\mathrm{P}-1$. Only compound $\mathbf{4}$ has crystallized in another crystal setting, in the monoclinic space group $\mathrm{P} 2_{1} / \mathrm{n}$. However, the number of crystallographically independent molecules is not the same (Table 1). While the para-nitro compound $\mathbf{3}$ does crystallize with only one molecule in the asymmetric unit $\left(Z^{\prime}=1\right)$, compounds without substituents at phenyl ring $\mathrm{C}$ are present with either two (compound 2, with 2,5-dichloro substituents at phenyl ring A) or three molecules (compound $\mathbf{1}$, without substituents at phenyl $\operatorname{ring} \mathrm{A}$ ) in the asymmetric unit. The 2,5-dichloro substituted compound $\mathbf{4}$ with para-nitro moiety at ring $\mathrm{C}$ does also contain two molecules in its asymmetric unit besides half of one ethyl alcohol molecule disordered over two $25 \%$ occupancy sites. Values of Z'>1 are a consequence of conformerism in the crystal phases of compounds $\mathbf{1 ,} \mathbf{2}$ and 4 . This phenomenon has been previously reported in one related chalcone sulfonamide. ${ }^{26}$ Here, the absence of para-nitro group at ring $\mathrm{C}$ is related to the conformational variability in compounds $\mathbf{1}$ and $\mathbf{2}$ as described in sequence. In 4 , this phenomenon seems to be related to crystallization of ethyl alcohol came from synthetic procedure and its different interaction modes with each sulfonamide chalcone conformer (see crystal packing description below). It is important to note that all conformers found in this study have been obtained from crystallization under slow evaporation of solvent (dichloromethane). We had not investigated in this study the polymorphism (and then any change in conformers number) of such compounds as a function of the crystallization conditions, but it is surely an interesting issue to be searched in future. The sulfonamide chalcone molecules found in the asymmetric unit of compounds 1-4 are shown in Figure 3, an ellipsoid plot of $30 \%$ probability.
The chalcone molecular backbones are featured by different levels of planarity in the conformers of compounds 1, 2 and 4 . The planarity of the chalcone backbone, defined as being rings $\mathrm{B}$ and $\mathrm{C}$ and the open-chain between them, does increase from conformer $\mathrm{A}$ to $\mathrm{C}$ in compound $\mathbf{1}$. This can be described by the root mean square deviation (RMSD) of the least-square mean plane calculated through the non-hydrogen atoms of chalcone skeleton and by the greatest atom deviation from this mean plane. Both planarity indicators do decrease from conformer A to C. Similarly, chalcone backbone of conformer B is more planar than that of conformer A in compound 2. Their planarity indicators are also shown in Figure 4, as well as those of compounds $\mathbf{3}$ and $\mathbf{4}$, which show an intermediate chalcone planarity among conformer B of $\mathbf{2}$ (most planar) and conformer A of $\mathbf{1}$ (less planar).

The conformational variability found in $\mathbf{1 , 2}$ and $\mathbf{4}$ can be interpreted as a consequence of slight rotations around the $\mathrm{C} 10-\mathrm{C} 13$ bond axis (Table 2), which displaces central ring B from the neighboring carbonyl group. For instance, there is good correlation between the value of $\mathrm{C} 11-\mathrm{C} 10-\mathrm{C} 13-\mathrm{C} 14$ torsion angle and planarity of chalcone skeleton. As this torsion value does decrease in conformers of $\mathbf{1 , 2}$ and $\mathbf{4}$, the planarity of chalcone group does increase. There are also slight rotations on the $\mathrm{C} 15-\mathrm{C} 16$ bond axis, twisting ring $\mathrm{C}$ from the $\mathrm{C} 14$ and $\mathrm{C} 15$ olefin carbons. Inspection of $\mathrm{C} 14-\mathrm{C} 15-\mathrm{C} 16-\mathrm{C} 21$ torsion angles does reveal that ring $\mathrm{C}$ is more bent in both conformers of compound 2 and $\mathbf{3}$ than in those of $\mathbf{1}$ and $\mathbf{4}$ (Table 2), even though no straight correlation between the rotation on $\mathrm{C} 15-\mathrm{C} 16$ bond axis and overall chalcone planarity can be found.

Besides, the differences in the planarity of chalcone moiety, another conformational variability of compound $\mathbf{1}$ is in its benzenesulfonamide moiety. In fact, the conformation of this moiety is the main intramolecular feature changing among its conformers. There is a rotation of ca. $180^{\circ}$ on the N1-C7 bond axis of conformer A, if conformers B and $\mathrm{C}$ are taken as references. Compared to conformers $\mathrm{B}$ and $\mathrm{C}$, the $\mathrm{S} 1-\mathrm{N} 1-\mathrm{C} 7-\mathrm{C} 8$ torsion of conformer $\mathrm{A}$ is changed by $176.9^{\circ}(\Delta \mathrm{S} 1-\mathrm{N} 1-\mathrm{C} 7-\mathrm{C} 8=\mid \mathrm{S} 1-\mathrm{N} 1-\mathrm{C} 7-\mathrm{C} 8$ of conformer A minus S1-N1-C7-C8 of conformer B |) and by $175.7^{\circ}(\Delta \mathrm{S} 1-\mathrm{N} 1-\mathrm{C} 7-\mathrm{C} 8=\mid \mathrm{S} 1-\mathrm{N} 1-\mathrm{C} 7-\mathrm{C} 8$ of conformer A minus S1-N1-C7-C8 of conformer C (), respectively. Again, taking the chalcone plane as reference, ring $\mathrm{A}$ is on the same side in conformers $\mathrm{B}$ and $\mathrm{C}$, as well as their $\mathrm{SO}_{2}$ oxygen's are on the same side, which are opposed to ring $\mathrm{A}$. As a consequence of this rotation, ring $\mathrm{A}$ and $\mathrm{SO}_{2}$ oxygen's of conformer $\mathrm{A}$ are on opposite sides of the corresponding moieties in conformers $\mathrm{B}$ and $\mathrm{C}$.

Another consequence of this conformational change resides in the fact that $\mathrm{NH}$ hydrogen of conformer $\mathrm{A}$ is 
Table 1. Crystal data and refinement statistics for the sulfonamide chalcone derivatives prepared in this study

\begin{tabular}{|c|c|c|c|c|}
\hline & 1 & 2 & 3 & 4 \\
\hline Structural formula & $\mathrm{C}_{21} \mathrm{H}_{17} \mathrm{~N}_{1} \mathrm{O}_{3} \mathrm{~S}_{1}$ & $\mathrm{C}_{21} \mathrm{H}_{15} \mathrm{Cl}_{2} \mathrm{~N}_{1} \mathrm{O}_{3} \mathrm{~S}_{1}$ & $\mathrm{C}_{21} \mathrm{H}_{16} \mathrm{~N}_{2} \mathrm{O}_{5} \mathrm{~S}_{1}$ & $\left(\mathrm{C}_{21} \mathrm{H}_{14} \mathrm{Cl}_{2} \mathrm{~N}_{2} \mathrm{O}_{5} \mathrm{~S}_{1}\right)\left(\mathrm{C}_{2} \mathrm{H}_{6} \mathrm{O}_{1}\right)_{0.25}$ \\
\hline Formula weight / $\left(\mathrm{g} \mathrm{moL}^{-1}\right)$ & 363.42 & 432.30 & 408.42 & 489.58 \\
\hline Crystal dimension $/ \mathrm{mm}^{3}$ & $0.32 \times 0.13 \times 0.05$ & $0.28 \times 0.15 \times 0.05$ & $0.30 \times 0.10 \times 0.05$ & $0.21 \times 0.14 \times 0.09$ \\
\hline Crystal system & triclinic & triclinic & triclinic & monoclinic \\
\hline Space group & $\mathrm{P}-1$ & $\mathrm{P}-1$ & $\mathrm{P}-1$ & $\mathrm{P}_{1} / \mathrm{n}$ \\
\hline $\mathrm{Z} / \mathrm{Z}$ & $6 / 3$ & $4 / 2$ & $2 / 1$ & $8 / 2$ \\
\hline Temperature / K & $296(2)$ & $296(2)$ & $296(2)$ & $293(2)$ \\
\hline \multicolumn{5}{|l|}{ Unit cell dimension } \\
\hline$a / \AA$ & $12.6099(3)$ & $12.4498(4)$ & $5.5020(2)$ & $13.866(2)$ \\
\hline$b / \AA$ & $14.3280(3)$ & $13.1011(4)$ & $9.0690(2)$ & $15.960(3)$ \\
\hline$c / \AA$ & $16.2600(4)$ & $15.2911(4)$ & $18.8980(5)$ & 21.944(4) \\
\hline$\alpha /$ degree & $86.7298(13)$ & $99.5990(15)$ & $97.208(2)$ & 90 \\
\hline$\beta /$ degree & $71.6759(12)$ & $109.2174(14)$ & $91.028(2)$ & $92.211(4)$ \\
\hline$\gamma /$ degree & $81.9561(17)$ & $114.9782(14)$ & $94.646(2)$ & 90 \\
\hline Volume / $\AA^{3}$ & $2761.10(11)$ & $1993.98(11)$ & $932.06(5)$ & $4852.6(14)$ \\
\hline Calculated density / $\left(\mathrm{mg} \mathrm{m}^{-3}\right)$ & 1.311 & 1.440 & 1.455 & 1.340 \\
\hline Absorption coefficient $(\mu) / \mathrm{mm}^{-1}$ & 0.196 & 0.453 & 0.211 & 0.388 \\
\hline$\theta$ range for data collection / degree & 2.96 to 26.37 & 2.92 to 26.40 & 2.94 to 26.37 & 1.58 to 25.40 \\
\hline \multirow[t]{3}{*}{ Index range } & $-14 \leq h \leq 15$ & $-15 \leq h \leq 15$ & $-6 \leq h \leq 6$ & $-10 \leq h \leq 16$ \\
\hline & $-17 \leq k \leq 17$ & $-16 \leq k \leq 16$ & $-11 \leq k \leq 11$ & $-19 \leq k \leq 17$ \\
\hline & $-20 \leq l \leq 20$ & $-19 \leq l \leq 19$ & $-23 \leq l \leq 23$ & $-26 \leq l \leq 24$ \\
\hline Data collected & 20661 & 14707 & 6737 & 21763 \\
\hline Unique reflection & 11215 & 8013 & 3685 & 8872 \\
\hline Symmetry factor $\left(\mathrm{R}_{\mathrm{int}}\right)$ & 0.0482 & 0.0561 & 0.0361 & 0.0567 \\
\hline Completeness to $\theta_{\max } / \%$ & 99.2 & 98.0 & 96.6 & 99.3 \\
\hline $\mathrm{F}(000)$ & 1140 & 888 & 424 & 2010 \\
\hline Parameter refined & 703 & 505 & 262 & 593 \\
\hline Goodness-of-fit on $\mathrm{F}^{2}$ & 0.975 & 1.072 & 1.043 & 1.047 \\
\hline Final $\mathrm{R}_{1}$ factor for $\mathrm{I}>2 \sigma(\mathrm{I})$ & 0.0594 & 0.0844 & 0.0536 & 0.0738 \\
\hline$w \mathrm{R}_{2}$ factor for all data & 0.1898 & 0.3093 & 0.1680 & 0.2036 \\
\hline Largest diff. peak and hole / $\left(\mathrm{e} \AA^{-3}\right)$ & 0.213 and -0.272 & 0.541 and -0.387 & 0.195 and -0.264 & 0.853 and -0.659 \\
\hline CCDC deposit number & 1053443 & 1053444 & 1053445 & 1053446 \\
\hline
\end{tabular}

CCDC: Cambridge crystallographic data centre.

pointed toward an opposite side of that of conformers B and C. Besides seen in Figure 3, such conformational features can be also viewed in Figure 5, a superimposition of molecules found in asymmetric unit of compounds 1-4 though their chalcone mean plane.

In addition, there are also slight rotations about the sulfamyl S1-N1 and sulfonyl S1-C1 bond axes in the conformers of compounds $\mathbf{1}$ and $\mathbf{2}$. Analysis of the $\mathrm{C} 1-\mathrm{S} 1-\mathrm{N} 1-\mathrm{C} 7$ and $\mathrm{N} 1-\mathrm{S} 1-\mathrm{C} 1-\mathrm{C} 2$ torsion angles does show that the rotational freedom on the $\mathrm{S} 1-\mathrm{N} 1$ bond axis is less than that on $\mathrm{S} 1-\mathrm{C} 1$ in compound $\mathbf{1}$, while an opposed trend in their rotational freedom is observed in compound $\mathbf{2}$.
The largest gaps between the values of the $\mathrm{C} 1-\mathrm{S} 1-\mathrm{N} 1-\mathrm{C} 7$ and $\mathrm{N} 1-\mathrm{S} 1-\mathrm{C} 1-\mathrm{C} 2$ torsions are $6.1^{\circ}$ and $11.5^{\circ}$, respectively, for the conformers $\mathrm{B}$ and $\mathrm{C}$ of $\mathbf{1}$, while these gaps are $16.4^{\circ}$ and $9.6^{\circ}$, for the conformers of 2 . Consequently, the conformation of ring $\mathrm{A}$ is also a few different in the conformers of both compounds. On contrary, the values of these two torsions are statistically equal between the conformers of $\mathbf{4}$, revealing their same ring A conformation.

Even though slight rotations on the S1-N1 bond axis are present in the conformers of $\mathbf{1}$, these practically do not affect the conformation of the whole ring $\mathrm{A}-\mathrm{SO}_{2}$ moiety. It is mainly driven by the rotation on $\mathrm{N} 1-\mathrm{C} 7$ bond axis, 

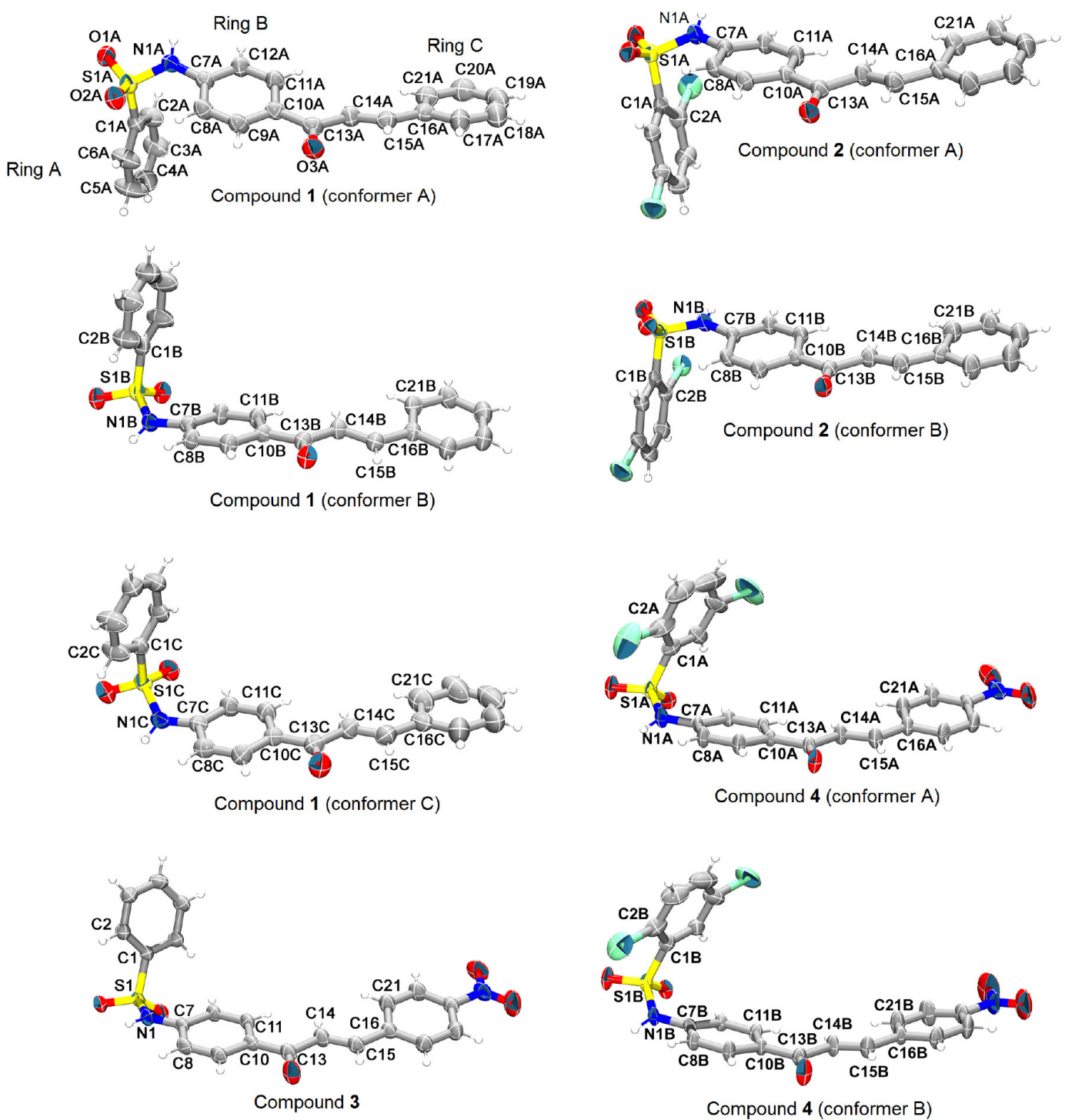

Figure 3. The conformers present in the asymmetric units of sulfonamide chalcones crystallographically elucidated in this study. Conformers are projected to the best view of their chalcone mean plane and benzenesulfonamide conformations (they are not shown as in their relative orientations into the chosen asymmetric unit). Non-hydrogen atoms are represented as $30 \%$ probability ellipsoids, while hydrogens are shown as arbitrary radius spheres. The labeling scheme of all non-hydrogen atoms and rings is shown for conformer A of $\mathbf{1}$, while only non-hydrogens atoms of the torsions selected to describe molecular conformation (given in Table 2) are labeled for the other conformers. Moreover, the same labeling scheme was used in all structures.

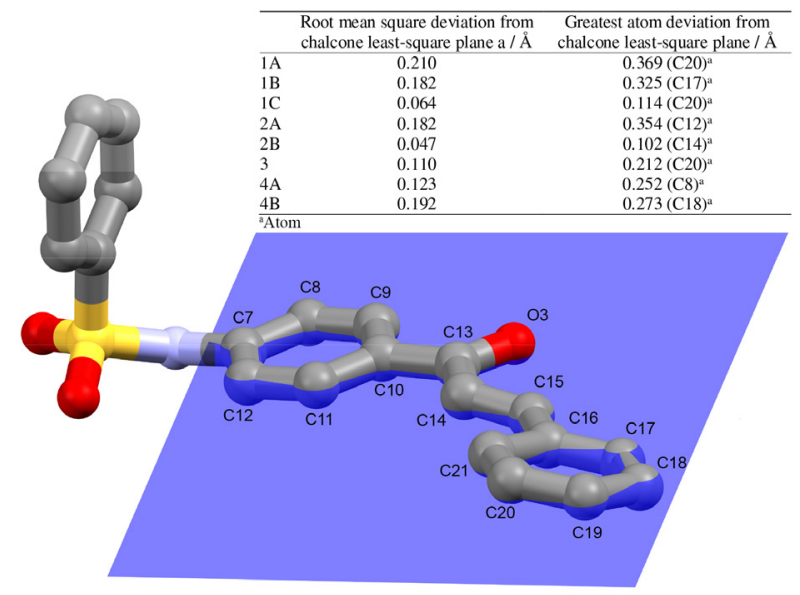

Figure 4. Descriptors for planarity of chalcone moiety (labeled atoms).

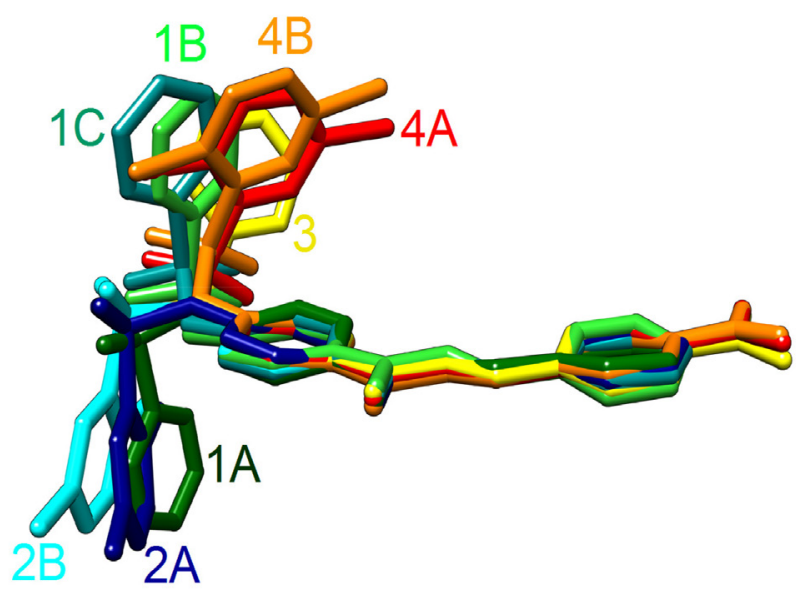

Figure 5. Molecular overlay through chalcone motif of compounds 1-4 
Table 2. Selected torsion angles for the conformationally variable sulfonamide chalcone derivatives elucidated here by single-crystal X-ray crystallography

\begin{tabular}{lccccc}
\hline \multirow{2}{*}{ Conformer } & \multicolumn{5}{c}{ Torsion angle / degree } \\
\cline { 2 - 6 } & $\mathrm{C} 1-\mathrm{S} 1-\mathrm{N} 1-\mathrm{C} 7$ & $\mathrm{~S} 1-\mathrm{N} 1-\mathrm{C} 7-\mathrm{C} 8$ & $\mathrm{~N} 1-\mathrm{S} 1-\mathrm{C} 1-\mathrm{C} 2$ & $\mathrm{C} 11-\mathrm{C} 10-\mathrm{C} 13-\mathrm{C} 14$ & $\mathrm{C} 14-\mathrm{C} 15-\mathrm{C} 16-\mathrm{C} 21$ \\
\hline 1A & $-63.8(2)$ & $-27.5(4)$ & $-57.8(3)$ & $-13.5(4)$ & $3.8(6)$ \\
1B & $-60.1(2)$ & $149.4(2)$ & $-50.0(3)$ & $5.4(4)$ & $1.2(4)$ \\
1C & $-66.2(3)$ & $148.2(2)$ & $-61.5(3)$ & $-4.9(5)$ & $-3.1(7)$ \\
2A & $-53.5(5)$ & $-30.1(7)$ & $-71.4(5)$ & $13.8(8)$ & $5.8(10)$ \\
2B & $-69.9(5)$ & $-0.3(7)$ & $-61.8(5)$ & $-3.1(8)$ & $8.3(11)$ \\
3 & $-75.01(18)$ & $-171.74(15)$ & $-75.33(16)$ & $1.9(3)$ & $8.5(3)$ \\
4A & $-52.0(8)$ & $154.2(7)$ & $-63.2(11)$ & $5.8(10)$ & $3.7(15)$ \\
4B & $-52.3(7)$ & $145.8(6)$ & $-63.6(9)$ & $8.0(12)$ & $-2.7(14)$ \\
\hline
\end{tabular}

as discussed above. In 2, however, the conformation around the $\mathrm{S} 1-\mathrm{N} 1$ bond axis contributes to the whole benzenesulfonamide conformation even because its conformers are not so different in terms of $\mathrm{N} 1-\mathrm{C} 7$ bond axis rotation as occurs in $\mathbf{1}$. The $\mathrm{S} 1-\mathrm{N} 1-\mathrm{C} 7-\mathrm{C} 8$ torsion differs for $29.8^{\circ}$ in conformers $\mathrm{A}$ and $\mathrm{B}$ of $\mathbf{2}$, against up to ca. $180^{\circ}$ in 1 (see above). Concerning the $\mathrm{Ph}-\mathrm{SO}_{2} \mathrm{NH}$ conformation, both conformers of $\mathbf{2}$ do resemble conformer A of $\mathbf{1}$. Furthermore, such rotation does not set ring $\mathrm{A}$ of the conformers on opposite sides in 2, likewise their $\mathrm{SO}_{2}$ oxygens are on the same side relative to chalcone plane. Furthermore, ring $\mathrm{A}$ and the chalcone backbone are almost perpendicular in all conformers of $\mathbf{1}$ and $\mathbf{2}$, with angles between their mean planes of $84.80(9)^{\circ}, 84.79(9)^{\circ}$, and $83.21(7)^{\circ}$ in conformers $\mathrm{A}, \mathrm{B}$ and $\mathrm{C}$ of $\mathbf{1}$, and $83.80(12)^{\circ}$ and $84.67(11)^{\circ}$ in conformers A and B of $\mathbf{2}$. These planes are not so bent in compound $\mathbf{3}$ and in conformers $\mathrm{A}$ and $\mathrm{B}$ of 4 , with the corresponding measurement of $70.57(4)^{\circ}$, $75.6(3)^{\circ}$ and $69.7(3)^{\circ}$, respectively. Compounds 3 and $\mathbf{4}$ are present with a benzenesulfonamide conformation similar to conformers $\mathrm{B}$ and $\mathrm{C}$ of $\mathbf{1}$. However, the values of the three torsions chosen here to describe the $\mathrm{Ph}-\mathrm{SO}_{2} \mathrm{NH}$ conformation (S1-N1-C7-C8, C1-S1-N1-C7 and N1-S1-C1-C2) can range from $2.4^{\circ}(\Delta \mathrm{S} 1-\mathrm{N} 1-\mathrm{C} 7-\mathrm{C} 8=\mid \mathrm{C} 1-\mathrm{S} 1-\mathrm{N} 1-\mathrm{C} 7$ of conformer $1 \mathrm{C}$ minus $\mathrm{C} 1-\mathrm{S} 1-\mathrm{N} 1-\mathrm{C} 7$ of conformer $4 \mathrm{~B} \mid$ ) to $40.1^{\circ}(\Delta \mathrm{S} 1-\mathrm{N} 1-\mathrm{C} 7-\mathrm{C} 8=\mid \mathrm{S} 1-\mathrm{N} 1-\mathrm{C} 7-\mathrm{C} 8$ of conformer $1 \mathrm{C}$ minus $\mathrm{S} 1-\mathrm{N} 1-\mathrm{C} 7-\mathrm{C} 8$ of compound $\mathbf{3}$, being this result subtracted from $360^{\circ}$ to get the lowest rotation converting one conformation into another one).

One can see that conformers of $\mathbf{4}$ are almost identical. In addition to the differences in chalcone core planarity discussed above, their $\mathrm{S} 1-\mathrm{N} 1-\mathrm{C} 7-\mathrm{C} 8$ torsion does also differ for $8.4^{\circ}$. This conformational change in the whole ring $\mathrm{A}-\mathrm{SO}_{2}$ moiety is a consequence of different hydrogen bonding patterns involving ring $\mathrm{A}$ and the solvent molecule crystallized in the lattice. Both ethyl alcohol fractions present in the asymmetric unit of $\mathbf{4}$ act as hydrogen bonding donor to sulfonamide chalcone conformers. However, $\pi$-system of ring $\mathrm{A}$ and $\mathrm{Cl} 1$ are the acceptors in conformers A and B, respectively (Figure 6). Therefore, the positioning of different hydrogen bonding acceptors of ring $\mathrm{A}$ is achieved by rotating slightly the N1-C7 bond axis. In turn, unlike ring $\mathrm{A}-\mathrm{SO}_{2}$ conformations are observed in these crystallographically independent molecules of $\mathbf{4}$.

In addition, inspection of bond lengths indicates that electron delocalization does not encompass the molecule backbone of all sulfonamide chalcone derivatives (Table 3). Bond lengths of the $\alpha, \beta$-unsaturated carbonyl and sulfonamide moieties and of the bridges between these moieties and phenyl rings are in good agreement with expected values for pure single and double bonds.

The analysis of the intermolecular interactions patterns keeping stable the three-dimensional network of the sulfonamide chalcones described in this study has revealed common features among them. Except for compound $\mathbf{3}$, there is formation of one-dimensional chains through classical intermolecular hydrogen bonds between $\mathrm{C}=\mathrm{O}$ oxygen from chalcone core and $\mathrm{N}-\mathrm{H}$ moiety from sulfonamide. Conformers A and B are alternately placed into these chains in compounds $\mathbf{2}$ and $\mathbf{4}$, acting both of them as hydrogen bonding donor and acceptor. A set of conformers $\mathrm{B}$, A to $\mathrm{C}$, in this order, is repeated into the ribbons in compound $\mathbf{1}$. In the last structure, conformer $\mathrm{B}$ does accept hydrogen bonding from conformer $\mathrm{C}$ and does donate to A, which, in turn, is a donor to C (Figure 7a). Furthermore, there are two ways of chain assembly, which are directly related to conformational variability around $\mathrm{N} 1-\mathrm{C} 7$ and $\mathrm{S} 1-\mathrm{N} 1$ bond axes. In compounds $\mathbf{1}$ and $\mathbf{4}$, as well as in the precedent crystal structures of $\mathbf{5}$ and $\mathbf{6},{ }^{26}$ the phenyl A rings of adjacent molecules are always oriented towards a same side if chalcone mean plane is taken as a reference, while these rings are alternately placed above and below the plane passing through the chalcone backbone in compound 2 (Figure 8a). 


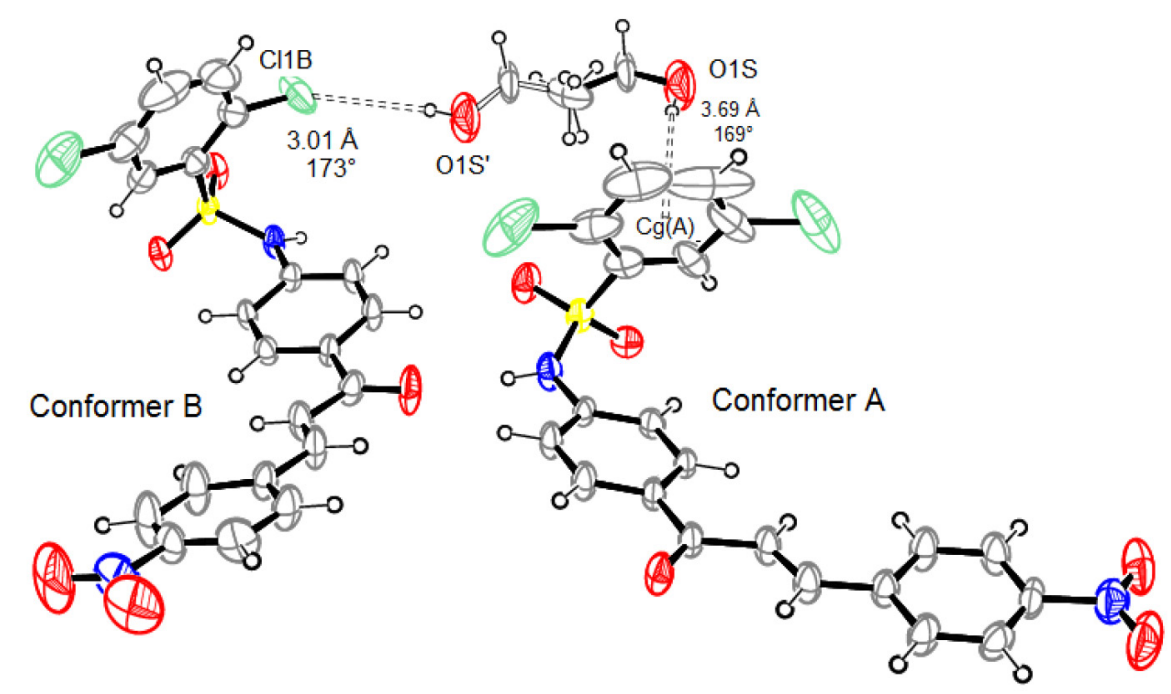

Figure 6. Hydrogen bonds (dashed lines) involving ethyl alcohol fractions and conformers A and B of compound 4. Non-hydrogen atoms are represented as $30 \%$ probability ellipsoids for both conformers and solvent fractions. Observe that the two fractions are superimposed through their methyl carbon, which is on only one 50\% occupancy site (all other ethyl alcohol atoms are in 25\% occupancy sites). Bonds between non-hydrogen atoms of ethyl alcohol are drawn as solid bonds in one fraction and as open bonds in another one. In this picture and in all next illustrations, only non-hydrogen atoms involved showing intermolecular contacts are labeled, as well as the displayed measurements refer to hydrogen acceptor atom $(\mathrm{Cg})$ distance and hydrogen bonding angle. $\mathrm{Cg}(\mathrm{A})$ denotes the centroid calculated through ring A carbons of conformer $\mathrm{A}$.

Table 3. Selected bond lengths for sulfonamide chalcone derivatives 1-4

\begin{tabular}{|c|c|c|c|c|c|c|c|c|}
\hline \multirow{3}{*}{ Bond } & \multicolumn{8}{|c|}{ Bond length / Å } \\
\hline & \multicolumn{3}{|c|}{1} & \multicolumn{2}{|c|}{2} & \multirow{2}{*}{3} & \multicolumn{2}{|c|}{4} \\
\hline & A & B & $\mathrm{C}$ & A & B & & A & B \\
\hline $\mathrm{C} 10-\mathrm{C} 13$ & $1.484(4)$ & $1.483(4)$ & $1.485(4)$ & $1.484(7)$ & $1.476(5)$ & $1.484(3)$ & $1.494(9)$ & $1.480(2)$ \\
\hline C13-C14 & $1.472(5)$ & $1.476(4)$ & $1.475(6)$ & $1.471(6)$ & $1.460(9)$ & $1.480(3)$ & $1.480(2)$ & $1.490(2)$ \\
\hline $\mathrm{C} 14-\mathrm{C} 15$ & $1.316(4)$ & $1.325(4)$ & $1.324(5)$ & $1.330(1)$ & $1.314(6)$ & $1.319(3)$ & $1.290(2)$ & $1.290(2)$ \\
\hline $\mathrm{C} 15-\mathrm{C} 16$ & $1.456(4)$ & $1.464(3)$ & $1.475(7)$ & $1.445(7)$ & $1.458(9)$ & $1.459(3)$ & $1.470(2)$ & $1.470(2)$ \\
\hline C13-O3 & $1.227(3)$ & $1.228(4)$ & $1.214(4)$ & $1.230(6)$ & $1.235(6)$ & $1.219(3)$ & $1.220(8)$ & $1.220(2)$ \\
\hline $\mathrm{N} 1-\mathrm{C} 7$ & $1.420(3)$ & $1.415(3)$ & $1.420(4)$ & $1.413(7)$ & $1.423(4)$ & $1.400(2)$ & $1.406(9)$ & $1.414(9)$ \\
\hline N1-S1 & $1.632(3)$ & $1.632(2)$ & $1.635(2)$ & $1.617(4)$ & $1.625(5)$ & $1.627(2)$ & $1.613(7)$ & $1.618(6)$ \\
\hline $\mathrm{S} 1-\mathrm{O} 1$ & $1.421(2)$ & $1.424(2)$ & $1.421(3)$ & $1.421(5)$ & $1.423(3)$ & $1.427(2)$ & $1.434(6)$ & $1.413(6)$ \\
\hline $\mathrm{S} 1-\mathrm{O} 2$ & $1.420(2)$ & $1.426(2)$ & $1.423(3)$ & $1.426(5)$ & $1.437(5)$ & $1.427(2)$ & $1.410(7)$ & $1.431(6)$ \\
\hline $\mathrm{S} 1-\mathrm{C} 1$ & $1.757(3)$ & $1.758(3)$ & $1.757(3)$ & $1.765(5)$ & $1.778(7)$ & $1.764(2)$ & $1.790(2)$ & $1.777(9)$ \\
\hline
\end{tabular}

In the case of compound $\mathbf{2}$, this is related to the assembly of chains with conformers owing similar benzenesulfonamide conformations, i.e., same enantiomorphs of molecules $\mathrm{A}$ and $\mathrm{B}$ are found into each chain. As expected from head-to-tail disposition of chalcone skeletons and from a zigzag fashion of hydrogen bonds into the chains, the side benzene heads are not on a same side relative to the aligned molecular mean planes in this structure.

On the other hand, different enantiomorphs of conformers A and B have their chalcone mean planes head-to-head aligned into each chain in crystal structure of compound $\mathbf{4}$, which forces rings A to lie on same side relative to chain backbone (Figure 9a). This behavior is also found in compound $\mathbf{1}$ present with distinct enantiomorphs of conformers $\mathrm{B}$ and $\mathrm{C}$ into the chains. In this structure, conformer A is enantiomorphically related to conformer B, but the rotation of ca. $180^{\circ}$ on its $\mathrm{N} 1-\mathrm{C} 7$ bond axis relative to the conformational counterpart is responsible for setting its ring $\mathrm{A}$ in the same side where this moiety from the two other conformers is found.

Also in crystal structure of $\mathbf{1}$, chalcone plane can be oriented in either head-to-head (A towards B and B towards C) or head-to-tail (A towards C) manners. Besides this classical hydrogen bonding pattern contributing primarily to the crystal packing of the compounds, $\mathrm{C}-\mathrm{H} \ldots \pi$ and $\pi \ldots \pi$ interactions take place in compounds without 


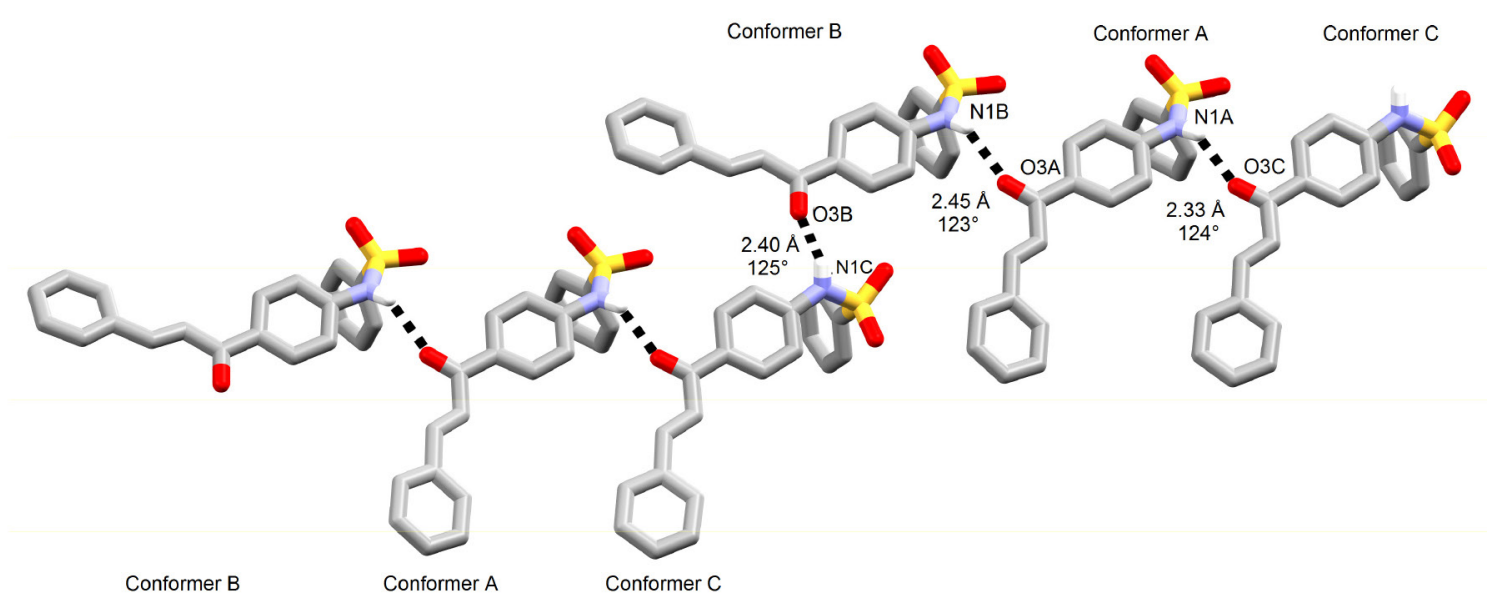

(a)

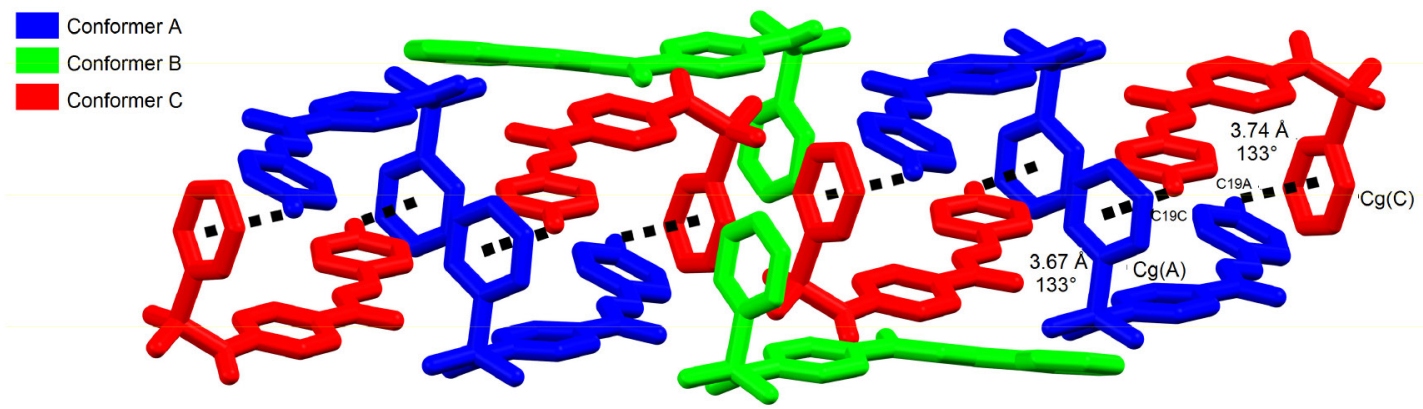

(b)

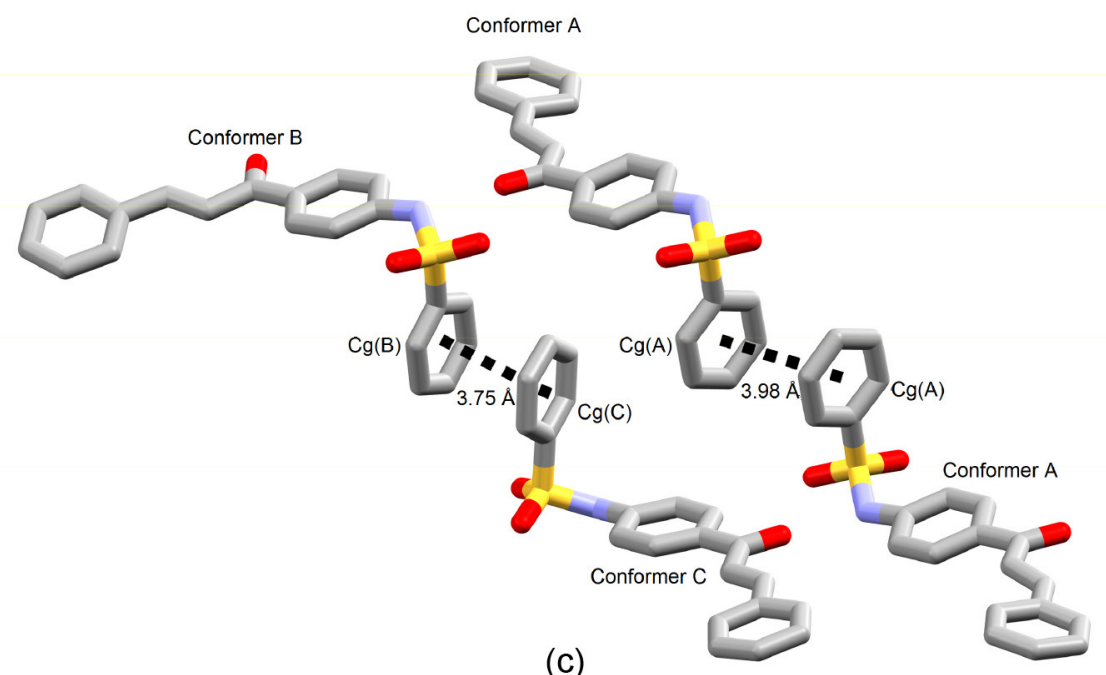

(c)

Figure 7. (a) Primary chain of 1 assembled with classical hydrogen bonds; (b) stacking of two primary chains through C-H... $\pi$ contacts; (c) $\pi \ldots \pi$ interactions responsible for linking the primary chains at their side. $\operatorname{Cg}(\mathrm{A}), \mathrm{Cg}(\mathrm{B})$ and $\operatorname{Cg}(\mathrm{C})$ denote the centroid calculated through ring $\mathrm{A}$ carbons of conformers A, B and C, respectively.

nitro group, while nonclassical $\mathrm{C}-\mathrm{H} \ldots \mathrm{O}_{\text {(nitro) }}$ are major in both nitro derivatives. These interactions are responsible for the aforementioned conformational features on the $\mathrm{S} 1-\mathrm{C} 1$ bond axis (ring A conformation only) and for slight chalcone planarity deviations. It is striking to note that this last conformational characteristic is also a result from classical hydrogen bonds into the chains positioning carbonyl oxygen to interact with amino moiety.

Contacts of the $\mathrm{C}-\mathrm{H} \ldots \pi$ type are responsible to face-to-face stack one chain on top of another one in 


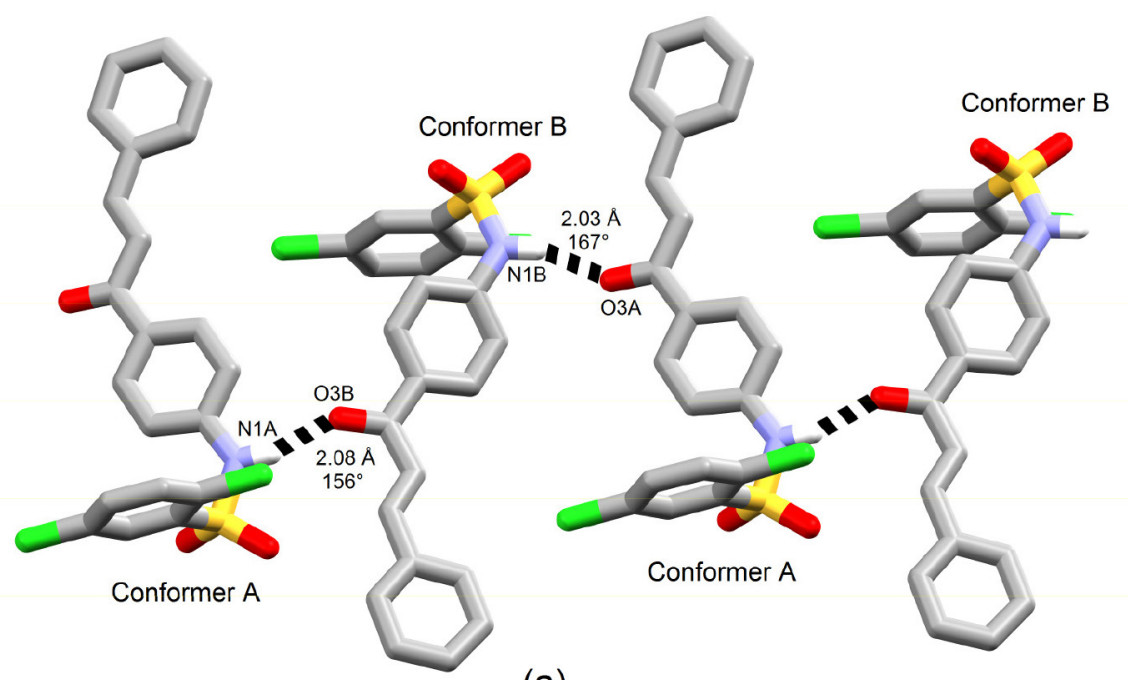

(a)
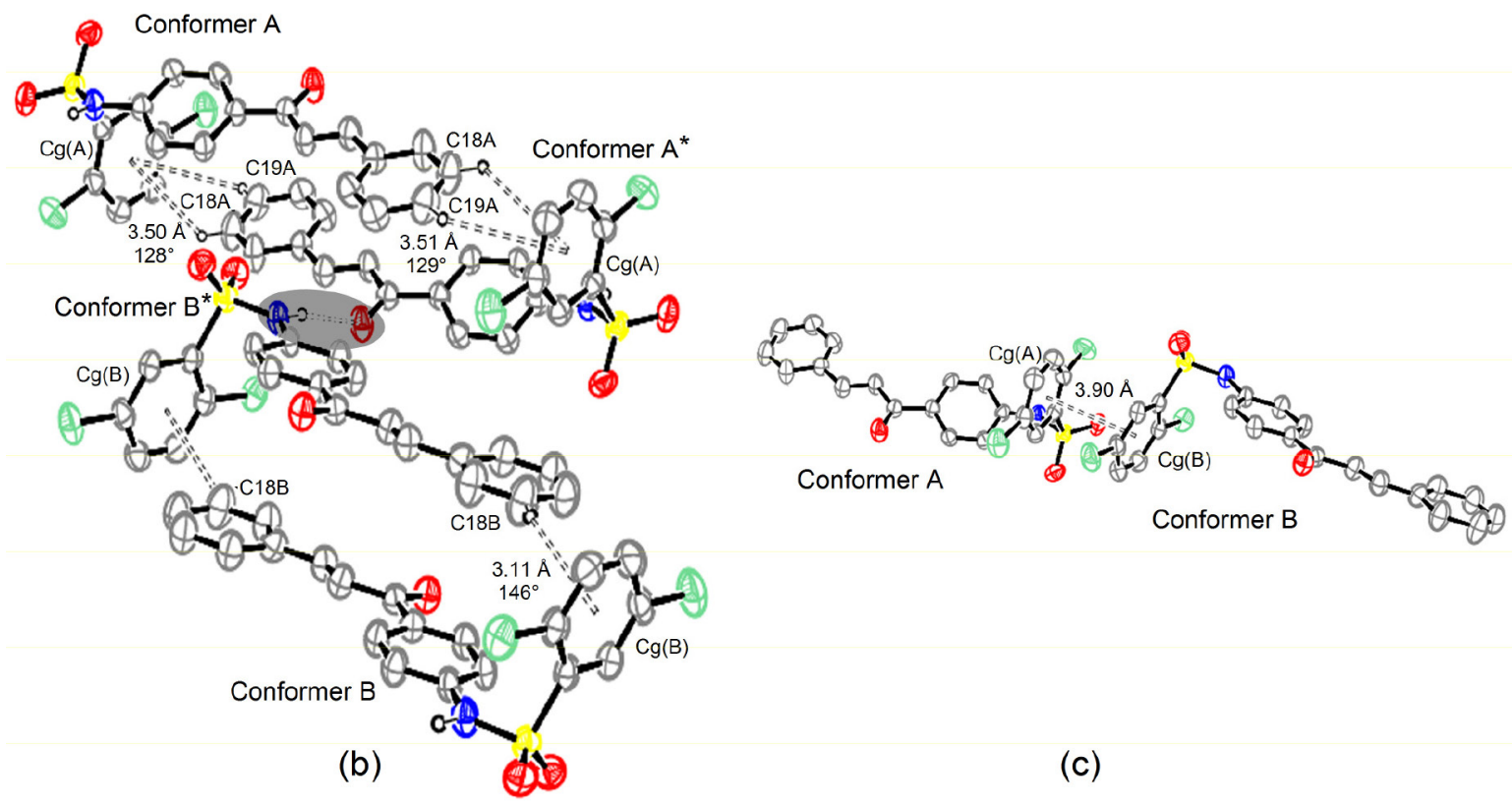

Figure 8. (a) The primary chain of $\mathbf{2}$ formed though classical hydrogen bonds; (b) C-H... $\pi$ contacts cross-linking primary chains below and above the chain backbone (one classical hydrogen bond is shadowed to highlight two asterisk-labeled molecules belonging to one same primary chain); (c) $\pi \ldots \pi$ interactions connecting the primary chains at their side. In panels (b) and (c), 30\% probability ellipsoids draw the non-hydrogen atoms. $\mathrm{Cg}(\mathrm{A})$ and $\mathrm{Cg}(\mathrm{B})$ denote the centroid calculated through ring A carbons of conformers A and B, respectively.

compounds $\mathbf{1}$ and $\mathbf{2}$, while $\pi \ldots \pi$ interactions does contact them at their side. In $1, \mathrm{C}-\mathrm{H} . . . \pi$ interactions occur between conformers $\mathrm{A}$ and $\mathrm{C}$ only, with face-to-face stacking of an entire chain on another one (Figure 7b). In this structure, all conformers are involved in $\pi \ldots \pi$ interactions, as well as in $\mathbf{2}$ (Figures $7 \mathrm{c}$ and $6 \mathrm{c}$ ). In $\mathbf{2}$, however, $\mathrm{C}-\mathrm{H} \ldots \pi$ interactions occurring between same conformers are cross-linking the chains above and below the chain backbone, even because of its alternate phenyl A ring disposition along the ribbon (Figure $8 \mathrm{~b}$ ). In $\mathbf{4}$, there is formation of twodimensional sheets due to the presence of secondary nonclassical hydrogen bonded chains along with the primary one assembled through classical hydrogen bonds (see above). In these sheets, nitro groups of both conformers act as hydrogen bonding acceptors from $\mathrm{C}-\mathrm{H}$ moieties of chalcone motif and all phenyl A ring stays towards a same side of the sheet (Figure 9). Such non-classical hydrogen bonds are also observed in compound $\mathbf{3}$. However, carbonyl oxygen is a non-classical hydrogen bonding acceptor from a $\mathrm{C}-\mathrm{H}$ moiety of chalcone besides nitro ones (Figure 10b). In fact, sheets are made up of non-classical hydrogen bonds in this structure. They are further contacted through classical intermolecular hydrogen bonds between sulfonamide moieties, wherein amino group is a bifurcated hydrogen bonding donor to both $\mathrm{SO}_{2}$ oxygens (Figure 10a). The crystal packing inspection performed here can give us 


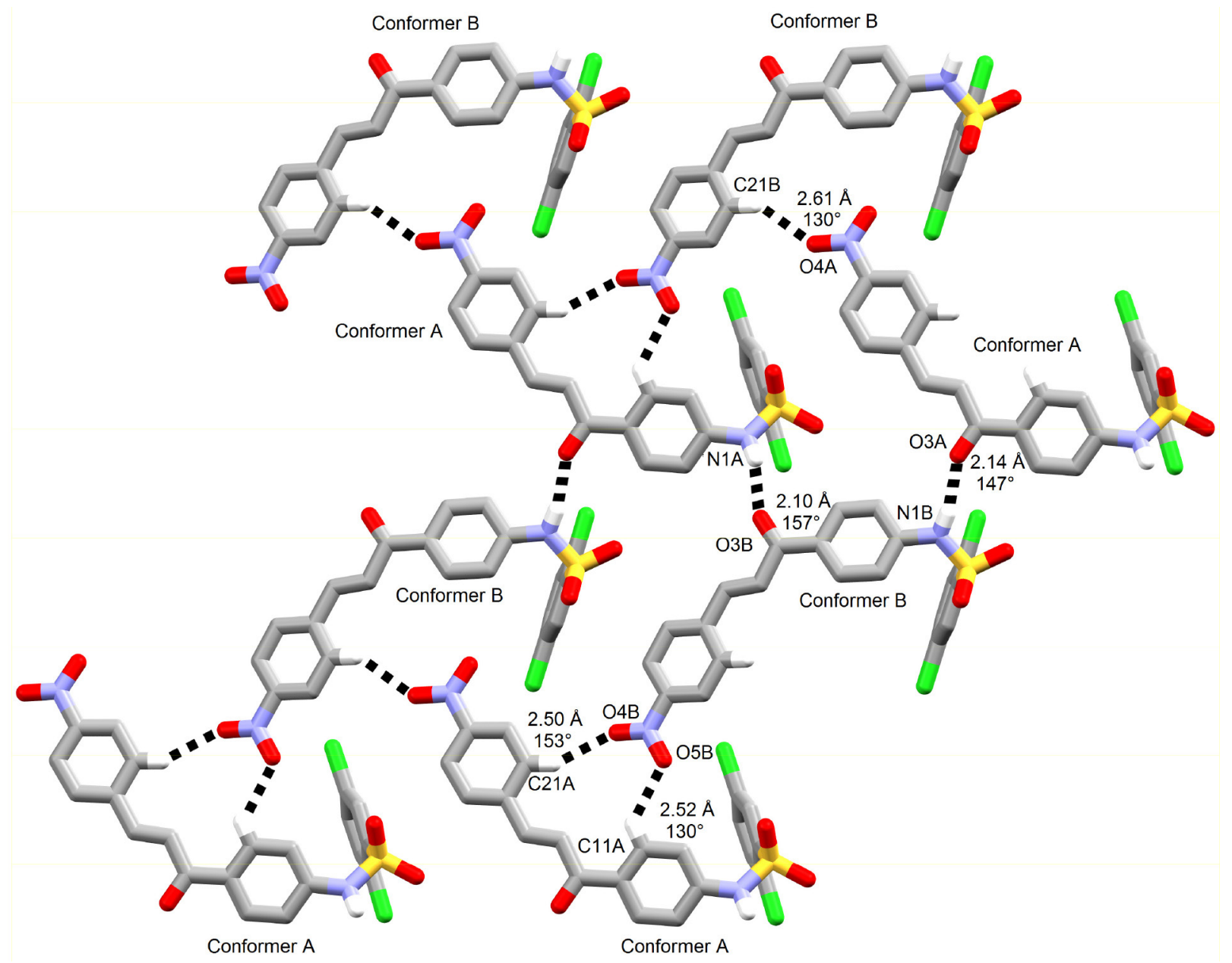

Figure 9. The two-dimensional sheet found in the crystal structure of 4 .

meaningful insights on how sulfonamide chalcone hybrids are interacting with target biological macromolecules. They can bind to hydrophilic amino acid residues through strong hydrogen bonds by mean of their sulfonamide moiety and carbonyl group from chalcone part whilst its side benzene ring can simultaneously interact with hydrophobic amino acid residues through cooperative $\mathrm{C}-\mathrm{H} \ldots \pi$ and $\pi \ldots \pi$ interactions.

\section{Cytotoxic activity}

The four sulfonamide chalcone derivatives prepared in this study were evaluated for their in vitro cytotoxic activity against three human cancer cell lines (HTC-8, MDA-MB-435 and SF-295). The cytotoxicity of two other analogues, which crystal structures were elucidated early by our research group, was also tested against these cultured cells. The results of the antiproliferative activity assay are shown in Tables 4 and 5. As can be viewed in Table 4, both sulfonamide chalcones with para-nitro group at ring $\mathrm{C}$ have almost entirely inhibited all cancer cell lines tested, except for MDA-MB-435 cell line which compounds $\mathbf{3}$ and $\mathbf{4}$ inhibited ca. 70\%. Therefore, a very broad spectrum of antiproliferative effects was observed for these compounds even at a low concentration, ranging from 0.19 to $25 \mu \mathrm{g} \mathrm{mL}^{-1}$. The relative potency of cell growth inhibition is shown in Table 5. Sulfonamide chalcones $\mathbf{3}$ and $\mathbf{4}$ have exhibited low $\mathrm{IC}_{50}$ values comparable to that of positive control (doxorrubicin), a stronger inhibitor of cancer cell growth. Their $\mathrm{IC}_{50}$ values range from 3.42 to $6.78 \mu \mathrm{mol} \mathrm{L}{ }^{-1}$ (compound 3) and from 6.84 to $8.10 \mu \mathrm{mol} \mathrm{L}^{-1}$ (compound 4). Under the same growth conditions, $\mathrm{IC}_{50}$ values of doxorrubicin range from 0.04 to $0.50 \mu \mathrm{mol} \mathrm{L} \mathrm{L}^{-1}$. These cell growth inhibition data indicates that the presence of para-nitro moiety at ring $\mathrm{C}$ is decisive for antiproliferative activity of the sulfonamide chalcone hybrids, whereas chlorine substitutions at ring A does not affect much cytotoxic activity. The last assumption is based on (i) the similar $\mathrm{IC}_{50}$ values of $\mathbf{3}$ and $\mathbf{4}$ and (ii) the weak cytotoxicity of compound 2 with 2,5-dichloro substitutions at ring $\mathrm{A}$ and without substituents at ring C (less than $40 \%$ against all 


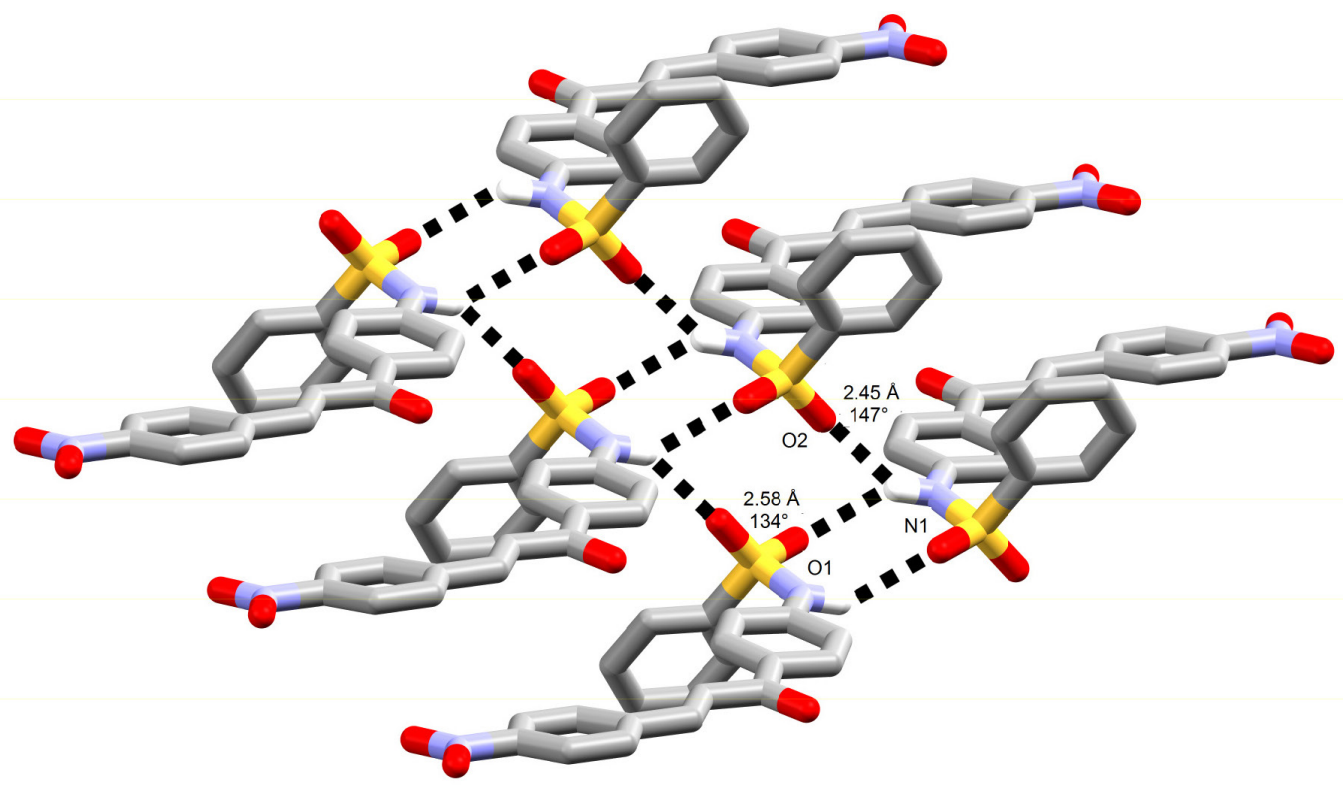

(a)

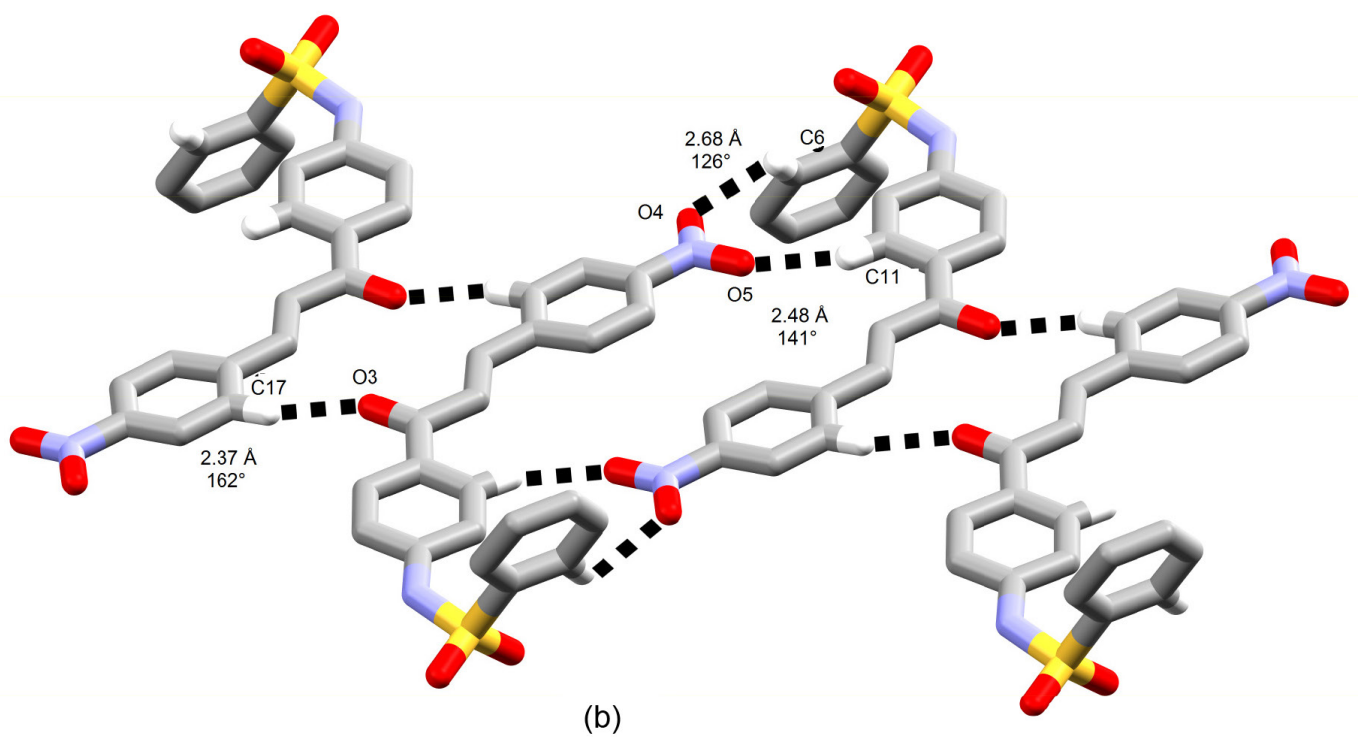

Figure 10. (a) Classical and (b) non-classical intermolecular contacts present in the compound $\mathbf{3}$ crystal lattice. In panel (a), chains as shown in panel (b) grow in the line with each chalcone mean plane.

tested cell lines at a $25 \mu \mathrm{g} \mathrm{mL} \mathrm{m}^{-1}$ concentration). In fact, all compounds of the series without para-nitro group were weakly active against the cancer cells evaluated in this study (Table 4).

In addition, the chalcones tested in this study also showed moderate cytotoxic activity against non-tumor peripheral blood mononuclear cells (PBMC) and murine fibroblast line (L929) (Table 5). The compounds showed selectivity index (the ratio between the $\mathrm{IC}_{50}$ values of the compounds for non-tumor and tumor cells) of about three times for tumor cells tested with respect to PBMC. In the murine fibroblast line L929, the compounds had a higher cytotoxicity, which has decreased the selectivity index for the carcinogenic strains when compared to the $\mathrm{IC}_{50}$ values for PBMC.

\section{Conclusions}

A new chalcone sulfonamide derivative has been provided and its crystal structure was determined. Crystal structures of other three related compounds have been also elucidated for the first time here. Furthermore, this study has meant an interesting example in which a molecular difference of only one nitro group in the para-position of 
Table 4. Cytotoxicity of sulfonamide chalcones 1-6 against three tumor cell lines

\begin{tabular}{lccc}
\hline Compound & HTC-8 & MDA-MB-435 & SF-295 \\
\hline $\mathbf{1}$ & $58.60 \pm 0.74$ & $18.72 \pm 29.49$ & $60.63 \pm 3.65$ \\
$\mathbf{2}$ & $39.39 \pm 2.10$ & $13.65 \pm 4.17$ & $35.93 \pm 0.00$ \\
$\mathbf{3}$ & $98.82 \pm 1.30$ & $70.59 \pm 46.50$ & $99.43 \pm 0.07$ \\
$\mathbf{4}$ & $95.59 \pm 1.30$ & $72.67 \pm 3.45$ & $100.00 \pm 0.51$ \\
$\mathbf{5}$ & $31.35 \pm 3.09$ & $0.00 \pm 3.72$ & $32.89 \pm 3.58$ \\
$\mathbf{6}$ & $68.69 \pm 3.27$ & $52.01 \pm 3.08$ & $63.68 \pm 6.65$ \\
Dexorrubicin $^{\mathrm{a}}$ & $96.60 \pm 0.10$ & $97.10 \pm 0.20$ & $97.40 \pm 0.10$ \\
\hline
\end{tabular}

aPositive control at $5 \mu \mathrm{g} \mathrm{mL}{ }^{-1}$; HTC-8: colon cancer; MDA-MB-435: melanoma; SF-295: central nervous system; tumor cell growth inhibition percentage (GI-\%) were measured at a compound concentration ranging from 0.19 to $25 \mu \mathrm{g} \mathrm{mL}-1$ and are shown as the average of three replicates followed by standard deviation.

Table 5. $\mathrm{IC}_{50}$ values of sulfonamide chalcones $\mathbf{3}$ and $\mathbf{4}$ against three cancer cell lines and two non-cancerous cells (PBMC and L929)

\begin{tabular}{lccccc}
\hline \multirow{2}{*}{ Compound } & \multicolumn{5}{c}{$\left.\mathrm{IC}_{50} /(\mu \mathrm{mol} \mathrm{L})^{-1}\right)^{\mathrm{a}}$} \\
\cline { 2 - 6 } $\mathbf{3}$ & HCT-8 & MDA-MB-435 & SF-295 & PBMC & L929 \\
$\mathbf{n}$ & $6.08(5.33-6.93)$ & $6.78(6.01-7.64)$ & $3.42(2.91-4.03)$ & $15.84(13.96-17.98)$ & $8.00(6.63-9.66)$ \\
Doxorubicin $^{\mathrm{b}}$ & $7.31(6.44-8.29)$ & $6.84(6.01-7.79)$ & $8.10(6.15-10.69)$ & $20.92(18.39-23.81)$ & $14.08(12.56-15.78)$ \\
\hline
\end{tabular}

${ }^{5} 50 \%$ inhibitory concentration and 95\% confidence interval; ${ }^{b}$ positive control; HTC-8: colon cancer; MDA-MB-435: melanoma; SF-295: central nervous system; PBMC: peripheral blood mononuclear cells; L929: murine fibroblast line.

a side phenyl ring has resulted in conformerism regardless of 2,5-dichloro substitutions at the another peripheral phenyl ring. Molecules with variable planarity levels of their chalcone moieties have crystallized in the lattice of compounds without para-nitro group. Moreover, conformerism has been also found in the 2,5-dichloro substituted analogue with para-nitro moiety. In this compound, such behavior was related to different hydrogen bond patterns with ethyl alcohol crystallized over two occupancy sites in the lattice. Molecules also differ for their benzenesulfonamide conformation, including even rotations of ca. $180^{\circ}$ on the bond axis bridging the sulfonamide and chalcone backbones.

All compounds synthesized here and two other related sulfonamide chalcones were also assessed for their cytotoxic activity against three cancer cell lines MDAMB-435, HCT-8 and SF-295; and health cell lines PBMC and L929. However, compounds were more cytotoxic for tumor cells. Compounds with para-nitro group in the side phenyl ring of chalcone motif were the most active ones among all those tested, revealing that nitro moiety does increase the cytotoxicity of sulfonamide chalcone derivatives. Chlorine at 2,5-positions of benzenesulfonamide does not affect much this biological property even because the compound with such substitutions and without para-nitro group was weakly active as found from its low cell growth inhibition.

\section{Experimental}

\section{General procedure for synthesis and crystallization}

Compounds 1 and 2 were synthesized by Claisen-Schmidt condensation from $\mathrm{N}$-(4-acetylphenyl)benzenesulfonamide with benzaldehyde and $p$-nitrobenzaldehyde, respectively. $N$-(4-Acetylphenyl)-2,5-dichlorobenzenesulfonamide was used for the synthesis of $\mathbf{3}$ and $\mathbf{4}$ with benzaldehyde and $p$-nitrobenzaldehyde, respectively. Sodium hydroxide in ethanol $(50 \%, \mathrm{~m} / \mathrm{m})$ was used as catalyst. The reactions were performed at $343 \mathrm{~K}$ for ca. $15 \mathrm{~h}$ for $\mathbf{1} ; 20 \mathrm{~h}$ for $\mathbf{2}$; $24 \mathrm{~h}$ for 3 ; and $16 \mathrm{~h}$ for 4 . In each case, the precipitate was recrystallized from dichloromethane to obtain single crystals suitable for single-crystal X-ray diffraction analysis. The reaction yields were 78, 82, 55 and $66 \%$ for 1-4, respectively, and their melting-point ranges were $143-145^{\circ} \mathrm{C}, 204-207{ }^{\circ} \mathrm{C}, 178-181^{\circ} \mathrm{C}$ and $210-214{ }^{\circ} \mathrm{C}$, respectively. The same procedures were performed for the synthesis of $\mathbf{5}$ and $\mathbf{6}$, using, however, $N$-(4-acetylphenyl) benzenesulfonamide with either $p$-etoxybenzaldehyde (5) or $p$-methoxybenzaldehyde (6). More details for synthesis carried out at Instituto de Química from Universidade Federal de Goiás, yield and melting point of $\mathbf{5}$ and $\mathbf{6}$ can be found in another related paper. ${ }^{26}$ Full characterization of synthesized compounds can be found in the Supplementary Information. 
Structure determination by single-crystal X-ray diffraction technique

Selected crystals of $\mathbf{1 - 4}$ were mounted on a $\kappa$-goniostat and exposed at room temperature to graphitemonochromated X-ray beam (Mo K $\alpha, \lambda=0.71073 \AA$ ) using an Enraf-Nonius Kappa-CCD (Rotterdam, The Netherlands) diffractometer equipped with a CCD camera of 95 mm, installed on Instituto de Física de São Carlos, Universidade de São Paulo.

The crystallographic softwares were used as follows: COLLECT $^{40}$ (X-ray diffraction collect strategy with $\varphi$ scans and $\omega$ scans and with $\kappa$ offsets, besides frame acquision monitoring), HKL Denzo-Scalepack ${ }^{41}$ package of softwares (indexing, integration and scaling of raw data), SHELXS-97 $7^{42}$ (structure solving and structure refinement), Mercury CSD $2.0^{43}$ (structure analysis) and ORTEP-3 ${ }^{44}$ (graphical representations). The structures were solved using the direct methods of phase retrieval. All non-hydrogen atoms of asymmetric unit were promptly assigned from the electronic density Fourier synthesis. After their assignment, positional and thermal parameters were refined by full-matrix least squares method based on $\mathrm{F}^{2}$. Free anisotropic and fixed isotropic atomic displacement parameters were used for non-hydrogen and hydrogen atoms, respectively. The isotropic thermal displacement parameters of the $\mathrm{C}-\mathrm{H}$ and $\mathrm{N}-\mathrm{H}$ hydrogen atoms were $20 \%$ greater than the equivalent isotropic parameter of the corresponding atom. This value was set to $50 \%$ in the case of hydroxyl and methyl hydrogens of ethyl alcohol. The $\mathrm{C}-\mathrm{H}, \mathrm{N}-\mathrm{H}$ and $\mathrm{O}-\mathrm{H}$ bond distances were stereochemically defined according to riding model and, therefore, positional parameters of hydrogens were constrained in the refinements. Equal populations of disordered ethyl alcohol molecules superimposed through their methyl carbon have occurred in the crystal structure of 4. Site occupancy factors (sof) were set to $25 \%$ for the disordered atomic fractions of each ethyl alcohol molecule in one of the two orientations, except the superimposed methyl carbon that had $50 \%$ occupancy in its only corresponding site. Before sof constraints, these parameters were refined freely to find their value.

\section{Cell line and cell culture}

All cytotoxicity assays were carried out in the Laboratório Nacional de Oncologia Experimental at Universidade Federal do Ceará. The cell lines (Table 6) used in this work were obtained from the National Cancer Institute (Bethesda, MD, USA). ${ }^{45}$ The cells were maintained in RPMI 1640 medium supplemented with $10 \%$ fetal bovine serum, $2 \mathrm{mM}$ glutamine, $100 \mathrm{U} \mathrm{mL}^{-1}$ penicillin and
$100 \mu \mathrm{g} \mathrm{mL} \mathrm{m}^{-1}$ streptomycin at $37^{\circ} \mathrm{C}$ with $5 \% \mathrm{CO}_{2}$. Peripheral blood mononuclear cells were also tested. Heparinized blood from healthy was collected and the PBMC were isolated via a standard method of density-gradient centrifugation over Ficoll-Hypaque. PBMC were washed and re-suspended at a concentration of $1 \times 10^{6}$ cells $\mathrm{mL}^{-1}$ in RPMI 1640 medium supplemented with $20 \%$ fetal bovine serum, $2 \mathrm{mM}$ glutamine, $100 \mathrm{U} \mathrm{mL}^{-1}$ penicillin and $100 \mu \mathrm{gL}^{-1}$ streptomycin at $37{ }^{\circ} \mathrm{C}$ with $5 \% \mathrm{CO}_{2}$. Lymphocytes were stimulated by addition of phytohemagglutinin in the culture medium at a concentration of $3 \%$. After $24 \mathrm{~h}$ of culture, the cells were treated with the sulfonamide chalcones.

Table 6. Cell lines used in this study and their culture concentration

\begin{tabular}{lcc}
\hline Cell line & $\begin{array}{c}\text { Histological type of } \\
\text { strain }(\text { origin })\end{array}$ & $\begin{array}{c}\text { Concentration of } \\
\text { plating } /\left(\text { cell } \mathrm{mL}^{-1}\right)\end{array}$ \\
\hline HCT-8 & colorectal carcinoma & $7 \times 10^{4}$ \\
MDA-MB-435 & melanoma & $3 \times 10^{5}$ \\
SF-295 & glioblastoma & $1 \times 10^{5}$ \\
L929 & murine fibroblast & $1 \times 10^{5}$ \\
PBMC & peripheral blood & $1 \times 10^{6}$ \\
& mononuclear cells & \\
\hline
\end{tabular}

Cytotoxicity assay

\section{MTT assay}

The evaluation of the cytotoxic effect of the chalcones was accomplished by colorimetric 3-(4,5-dimethyl-2thiazolyl)-2,5-diphenyl-2H-tetrazolium bromide (MTT) after $72 \mathrm{~h}$ of incubation. ${ }^{46,47}$ Briefly, cells in suspension or in monolayers were plated in 96-well plates. After $24 \mathrm{~h}$, sulfonamide chalcones $\left(0.19\right.$ to $\left.25 \mu \mathrm{g} \mathrm{mL}^{-1}\right)$ dissolved in sterile dimethyl sulfoxide (DMSO) were added to each well, and the cells were incubated for $72 \mathrm{~h}$. After incubation, plates were centrifuged and the supernatant discarded. Each well received $150 \mu \mathrm{L}$ of MTT solution at $0.5 \mathrm{mg} \mathrm{mL}^{-1}$ and they were incubated for $3 \mathrm{~h}$ in incubator with an atmosphere of $5 \% \mathrm{CO}_{2}$ at $37{ }^{\circ} \mathrm{C}$. Doxorubicin $\left(0.03\right.$ to $\left.5 \mu \mathrm{g} \mathrm{mL} \mathrm{m}^{-1}\right)$ was used as a positive control. Control groups received the same amount of sterile DMSO $(0.05 \%)$. This experiment was run in three replicates and all absorbance $(570 \mathrm{~nm})$ values were converted into a cell growth inhibition percentage (GI-\%) by the equation 1 :

GI- $\%=100-[(\mathrm{T} / \mathrm{C}) \times 100 \%]$

where $\mathrm{C}$ is the absorbance for the negative control and $\mathrm{T}$ was the absorbance in the presence of the tested extract. Those compounds that presented more than $85 \%$ of activity were selected to be tested at concentrations varying from 0.078 to $5 \mu \mathrm{g} \mathrm{mL}^{-1}$ to determine $\mathrm{IC}_{50}$ values by nonlinear 
regression using GraphPad Prism program, version 5.0 (GraphPad Software, La Jolla, CA, USA).

Alamar blue assay

To investigate the selectivity of sulfonamide chalcones toward normal proliferating cells, an Alamar blue assay was performed with PBMC after $72 \mathrm{~h}$ of drug exposure. Briefly, PBMC were plated in 96-well plates $\left(1 \times 10^{5}\right.$ cells per well in $100 \mu \mathrm{L}$ of medium containing phytohemagglutinin). After $24 \mathrm{~h}$, test compounds and doxorubicin (positive control), in the same concentration used in MTT assay, was added to each well, and the cells were incubated for $72 \mathrm{~h}$. Control groups received the same amount of sterile DMSO (0.05\%). Twenty-four hours before the end of the incubation, $10 \mu \mathrm{L}$ of a stock solution $\left(0.312 \mathrm{mg} \mathrm{mL}^{-1}\right)$ of Alamar blue (resazurin, Sigma-Aldrich, St. Louis, MO, USA) was added to each well. The absorbance was measured using a multiplate reader (DTX 880 Multimode Detector, Beckman Coulter, Inc., Fullerton, CA, USA). The drug effect was quantified as the percentages of the control absorbances at $570 \mathrm{~nm}$ (reduced) and $595 \mathrm{~nm}$ (oxidized).

\section{Supplementary Information}

Supplementary data [NMR, Fourier transform infrared (FTIR) spectra] are available free of charge at http://jbcs.sbq.org.br as PDF file.

Supplementary crystallographic data sets for 1-4 are available through the Cambridge Structural Data Base (e-mail address deposit@ccdc.cam.ac.uk or http://www. ccdc.cam.ac.uk/pages/Home.aspx), under deposition numbers shown in Table 1.

\section{Acknowledgments}

We thank the Conselho Nacional de Desenvolvimento Científico e Tecnológico (CNPq) for the financial support (process No. 472623/2011-7 - Universal 14/2011). F. T. M. also thanks the CNPq for research fellowship. C. C. S also thanks Fundação de Amparo à Pesquisa do Estado de Goiás (FAPEG) for the scholarship (Process No. 201410267000635). We are grateful to Prof PhD Javier Alcides Ellena from Instituto de Física de São Carlos for gentle access to the Enraf-Nonius Kappa-CCD diffractometer.

\section{References}

1. Maia, C. W.; Yaeghoobi, M.; Abd-Rahman, N.; Kang, Y. B.; Pichika, M. R.; Eur. J. Med. Chem. 2014, 77, 378.
2. Salum, L. B.; Altei, W. F.; Chiaradia, L. D.; Cordeiro, M. N. S.; Canevarolo, R. R.; Melo, C. P. S.; Winter, E.; Mattei, B.; Daghestani, H. N.; Silva, M. C. S.; Creczynski-Pasa, T. B.; Yunes, R. A.; Yunes, J. A.; Andricopulo, A. D.; Day, B. W.; Vogt, A.; Eur. J. Med. Chem. 2013, 63, 501.

3. Scozzafava, A.; Owa, T.; Mastrolorenzo, A.; Supuran, C. T.; Curr. Med. Chem. 2003, 10, 925.

4. Khloya, P.; Ceruso, M.; Ram, S.; Supuran, C. T.; Sharma, P. K.; Bioorg. Med. Chem. Lett. 2015, 16, 3208.

5. Alafeefy, A. M.; J. Enzyme Inhib. Med. Chem. 2015, 30, 189.

6. Yang, C.; Chen, S.; Zhou, M.; Li, Y.; Li, Y.; Zhang, Z.; Liu, Z.; Ba, Q.; Li, J.; Wang, H.; Yan, X.; Ma, D.; Wang, R.; ChemMedChem 2014, 9, 1436.

7. Awadallah, F. M.; El-Waei, T. A.; Hanna, M. M.; Abbas, S. E.; Ceruso, M.; Oz, B. E.; Guler, O. O.; Supuran, C. T.; Eur. J. Med. Chem. 2015, 96, 425.

8. Yang, J.; Zhou, S.; Ji, L.; Zhang, C.; Yu, S.; Li, Z.; Meng, X.; Bioorg. Med. Chem. Lett. 2014, 24, 5055.

9. Mun, J. Y.; Jabbar, A. A.; Devi, N. S.; Liu, Y.; van Meir, E. G.; Goodman, M. M.; Bioorg. Med. Chem. 2012, 20, 4590.

10. Passalacqua, T. G.; Dutra, L. A.; de Almeida, L.; Velasquez, A. M. A.; Torres, F. A. E.; Yamasaki, P. R.; dos Santos, M. B.; Regasini, L. O.; Michels, P. A. M.; Bolzani, V. S.; Graminha, M. A. S.; Bioorg. Med. Chem. Lett. 2015, 25, 3342.

11. Chen, W.; Ge, X.; Xu, F.; Zhang, Y.; Liu, Z.; Pan, J.; Song, J.; Dai, Y.; Zhou, J.; Feng, J.; Liang, G.; Bioorg. Med. Chem. Lett. 2015, 25, 2998.

12. Alam, M. S.; Rahman, S. M. M.; Lee, D.-U.; Chem. Pap. 2015, 69, 1118.

13. Singh, P.; Anand, A.; Kumar, V.; Eur. J. Med. Chem. 2014, 85, 758.

14. Wang, Z.; Yang, L.; Yang, X.; Zhang, X.; Synth. Commun. 2013, 43, 3093.

15. Mahapatra, D. M.; Bharti, S. K.; Asati, V.; Eur. J. Med. Chem. 2015, 98, 69 .

16. Mahapatra, D. K.; Asati, V.; Bharti, S. K.; Eur. J. Med. Chem. 2015, 92, 839 .

17. Tseng, C.-H.; Tzeng, C.-C.; Hsu, C.-Y.; Cheng, C.-M.; Yang, C.-N.; Chen, Y.-L.; Eur. J. Med. Chem. 2015, 96, 306.

18. Mujumdar, P.; Poulsen, S.-A.; J. Nat. Prod. 2015, 78, 1470.

19. Drews, J.; Science (Washington, DC, U. S.) 2000, 287, 1960.

20. Ghorab, M. M.; Ragab, F. A.; Heiba, H. I.; El-Gazzar, M. G.; Zahran, S. S.; Eur. J. Med. Chem. 2015, 92, 682.

21. Sahu, N. K.; Balbhadra, S. S.; Choudhary, J.; Kohli, D. V.; Curr. Med. Chem. 2012, 19, 209.

22. Lee, S.-A.; Lee, M.-S.; Ryu, H. W.; Kwak, T. K.; Kim, H.; Kang, M.; Jung, O.; Kim, H. J.; Park, K. H.; Lee, J. W.; Cancer Biol. Ther. 2011, 11, 330.

23. Lee, B.; Kang, W.; Shon, J.; Park, K. H.; Song, K.-S.; Liu, K.-H.; J. Korean Soc. Appl. Biol. Chem. 2014, 57, 31. 
24. Seo, W. D.; Kim, J. H.; Kang, J. E.; Ryu, H. W.; Curtis-Long, M. J.; Lee, H. S.; Yang, M. S.; Park, K. H.; Bioorg. Med. Chem. Lett. 2005, 15, 5514.

25. Seo, W. D.; Ryu, Y. B.; Curtis-Long, M. J.; Lee, C. W.; Ryu, H. W.; Jang, K. C.; Park, K. H.; Eur. J. Med. Chem. 2010, 45, 2010.

26. de Castro, M. R. C.; Aragão, A. Q.; Napolitano, H. B.; Noda-Perez, C.; Martins, F. T.; Acta Crystallogr., Sect. C: Struct. Chem. 2013, 69, 267.

27. Kim, J. H.; Ryu, H. W.; Shim, J. H.; Park, K. H.; Withers, S. G.; ChemBioChem 2009, 10, 2475.

28. Xiao, X.; Liu, X.; Dong, S.; Cai, Y.; Lin, L.; Feng, X.; Chem. Eur. J. 2012, 18, 15922.

29. Kim, S.-G.; Acta Crystallogr., Sect. E: Crystallogr. Commun. 2014, 70, o851.

30. Kothandaraman, P.; Rao, W.; Foo, S. J.; Chan, P. W. H.; Angew. Chem. Int. Ed. 2010, 49, 4619.

31. Jalal, S.; Bera, K.; Sarkar, S.; Paul, K.; Jana, U.; Org. Biomol. Chem. 2014, 12, 1759.

32. Ranjith, S.; SubbiahPandi, A.; Govindan, E.; Dhayalan, V.; MohanaKrishnan A. K.; Acta Crystallogr., Sect. E: Struct. Rep. Online 2011, 67, o844.

33. Ranjith, S.; SubbiahPandi, A.; Dhayalan, V.; MohanaKrishnan A. K.; Acta Crystallogr., Sect. E: Struct. Rep. Online 2011, 67, o1242.

34. Chakkaravarthi, G.; Panchatcharam, R.; Dhayalan, V.; MohanaKrishnan, A. K.; Manivannan, V.; Acta Crystallogr. Sect. E: Crystallogr. Commun. 2010, 66, o2957.

35. Domínguez, J. N.; Leon, C.; Rodrigues, J.; Domingues, N. G.; Gut, J.; Rosenthal, P.; Il Farmaco 2005, 60, 307.
36. Iqbal, H.; Prabhakar, V.; Sangith, A.; Chandrika, B.; Balasubramanian, R.; Med. Chem. Res. 2014, 23, 4383.

37. Moustafa, O. S.; Ahmad, R. A.; Phosphorus, Sulfur Silicon Relat. Elem. 2003, 178, 475.

38. El-Sharief, A. M. S.; Ammar, Y. A.; Mohamed, Y. A.; Zaki, M. E. A.; J. Indian Chem. Soc. 1984, 61, 537.

39. Jamode, V. S.; Chandak, H. S.; Bhagat, P. R.; J. Indian Chem. Soc. 2008, 85, 1169.

40. Enraf-Nonius; Collect; Program for Crystal Structure and Refinement; Nonius, B. V., The Netherlands, 1998.

41. Otwinowski, Z.; Minor, W. In Methods in Enzymology, 276; Carter Jr., C. W.; Sweet, R. M., eds.; Academic Press: New York, 1997, ch. 15.

42. Sheldrick, G. M.; Acta Crystallogr., Sect. A: Found. Adv. 2008, 64, 112.

43. Macrae, C. F.; Bruno, I. J.; Chisholm, J. A.; Edgington, P. R.; Mccabe, P.; Pidcock, E.; Monge, L. R.; Taylor, R.; van de Streek, J.; Wood, P. A.; J. Appl. Crystallogr. 2008, 41, 466.

44. Farrugia, L. J.; J. Appl. Crystallogr. 1997, 30, 565.

45. Skehan, P.; Storeng, R.; Scudiero, D.; Monks, A.; Mcmahon, J.; Vistica, D.; Warren, J. T.; Bodesch, H.; Kenney, S.; Boyd, M. R.; J. Natl. Cancer Inst. 1990, 82, 1107.

46. Mossman, T.; J. Immunol. Methods 1983, 65, 55.

47. Berridge, M. V.; Tan, A. S.; Mccoy, K. D.; Wang, R.; Biochemica 1996, $4,14$.

Submitted: October 14, 2015

Published online: December 2, 2015 